\title{
Role of Biofeedback in Optimizing Psychomotor Performance in Sports
}

Maman Paul*, MSPT; Kanupriya Garg, MSPT; Jaspal Singh Sandhu, PhD

\author{
Authors' Affiliation: \\ Faculty of Sports Medicine and \\ Physiotherapy, Guru Nanak Dev \\ University, Amritsar, India \\ * Corresponding Author; \\ Address: Faculty of Sports Medicine \\ and Physiotherapy, Guru Nanak Dev, \\ University, Amritsar-143005, India \\ E-mail: mamanpau18@gmail.com
}

Received: Jun 03, 2011

Accepted: Sep 25, 2011

Key Words: Heart Rate Variability Biofeedback; Psychomotor Performance; Response Time; Concentration; Shooting

\begin{abstract}
Purpose: Biofeedback is an emerging tool to acquire and facilitate physiological and psychological domains of the human body like response time and concentration. Thus, the present study aims at determining the reconstitution of psychomotor and performance skills in basketball players through biofeedback training.

Methods: Basketball players $(\mathrm{N}=30)$ with different levels of expertise (university, state and national) aged 18-28 years (both male and female) were randomly divided into 3 equal groups - Experimental group, Placebo group and Control group. The experimental group received Heart Rate Variability Biofeedback training for 10 consecutive days for 20 minutes that included breathing at individual's resonant frequency through a pacing stimulus; Placebo group was shown motivational video clips for 10 consecutive days for 10 minutes, whereas Control group was not given any intervention. At session 1,10 and 1 month follow up, heart rate variability, respiration rate, response time (reaction and movement time), concentration and shooting performance were assessed.
\end{abstract}

Results: Two way repeated measure ANOVA was used to simultaneously compare within and between group differences. Response time, concentration, heart rate variability, respiration rate and shooting differences were statistically significant in each group along with interaction of group and time $(P<0.001)$. Also, all the measures showed statistically significant inter group difference $(P<0.05)$.

Conclusion: The results of the study suggest that biofeedback training may help to train stressed athletes to acquire a control over their psychophysiological processes, thus helping an athlete to perform maximally.

Asian Journal of Sports Medicine, Volume 3 (Number 1), March 2012, Pages: 29-40

\section{INTRODUCTION}

$\mathrm{L}$ earning of motor skills is a crucial factor in the performance of a sportsperson. Motor learning can be defined as "a relatively permanent change in motor behaviour". Modifications in motor behaviour are a result of maturation, motivation or training factors (such as improvements in speed) ${ }^{[1]}$. The rate of learning and final task performance is affected by the amount of training, training conditions and quality of practice $^{[2]}$. Also, the coordination between the central nervous system and muscular system plays a critical role in acquisition of learned skills and thus, in responding correctly at the required spot.

As reaction time involves both central and peripheral components and function, reaction based testing may be used as a tool for assessing the athletes' readiness for competition. According to Lofthus, 1982 [3], "Reaction time provides an indirect index of the processing capability of central nervous system and a simple means of determining sensorimotor performances". According to Magill, 1998 $8^{[4]}$, "Reaction time is the interval between the onset of a signal (stimulus) and the initiation of a movement response". 
Movement time is the interval between the initiation and completion of the movement. Response time is the cumulative effect of reaction time as well as movement time ${ }^{[5]}$. It is the total time between the onset of a stimulus and completion of the action.

The anatomical basis for information processing is the extensive network of neural pathways and circuits. The intact and flexible neural network is essential for quick reaction time, better concentration and victory. A study investigated the effects of Electromyographic Biofeedback (EMG BFB) on reaction time and movement time and provided evidence of learning and improved performance through biofeedback in the experimental group ${ }^{[6]}$. Another study compared Electroencephalographic Biofeedback (EEG BFB) and Psychostimulants in treating attention deficit/ hyperactivity disorders. The EEG group manifested significant improvement in attention, impulse control, speed of information processing and consistency of attention on the Test of Variables of Attention (TOVA) ${ }^{[7]}$. Thus, to the authors' knowledge, there is no study to date which has revealed the effect of Heart Rate Variability Biofeedback (HRV BFB) on response time and concentration.

Athletes perform excellently when distractions are low. The key skill is to be able to identify and concentrate on the relevant performance cues at each moment of competition. Identification of interplay between concentration and performance helps an athlete focus on key performance cues and results in enhanced performance. Concentration changes with time and maintaining the intensity and focus of concentration is worth recognizing ${ }^{[8]}$.

In various team and individual sports, regulation and improvement of motor skills and psychomotor processes is a requirement for success. In a dynamic sport like basketball that requires an intensive training load, there is a need to satisfy the high demands placed on the athletes. Basketball requires special defensive and offensive maneuvers like blocking, rebounding, dribbling, passing and shooting ${ }^{[9]}$. Among these; shooting, a highly individualistic skill can be considered as the most contributing skill for determining the outcome of the game ${ }^{[10]}$. Self confidence and concentration helps the player to make the shot in a relaxed state. In basketball, delayed decision making (slow reactions) will hinder the skill, whether on offense or defense, which may ultimately predict the outcome of the game. Since shooting is a fast moving skill, the players have to react as quickly as possible for execution of the shot. Execution of a perfect shot requires processing of multiple relevant cues and signals at the same time, so a performer has to react as quickly as possible to more than one stimulus.

Psychophysiological research has also substantiated the relationship between psychomotor efficiency and physiological activity ${ }^{[11,12]}$. Biofeedback can be used as a potential way to support the learning process during training of cognitive and psychomotor skills. The HRV BFB provides easy to interpret information about autonomic nervous system modulation. It produces synchronization between the sympathetic and parasympathetic nervous system and moderates the heightened sympathetic activity to achieve a relaxed state of mind. The HRV BFB procedure ${ }^{[13]}$ is based on resonance properties of the cardiovascular system (CVS). To elicit high-amplitude oscillations in autonomic functions, the procedure uses paced breathing at each individual's resonant frequency (RF). Resonant frequency of an individual can be estimated as the highest amplitude of heart rate oscillations elicited by breathing ${ }^{[14]}$. High amplitude oscillations are elicited at this single frequency, accounting for higher total variability in heart rate ${ }^{[15]}$. Breathing at individual RF strengthens the closed loop system of baroreflexes and also the interactions between the sympathetic and parasympathetic nervous system ${ }^{[16]}$. Thus, HRV BFB directly targets and modulates activity of the autonomic nervous system. Efficacy of HRV $\mathrm{BFB}$ has been tested in a golfer to reduce competitive stress and anxiety. The results of the case study suggested that HRV BFB training may help the athlete to cope with stress and anxiety experienced before and during the competition ${ }^{[16]}$. Similarly, previous HRV BFB researches have also addressed optimization of maximum heart rate oscillations at varying resonant frequencies to enhance athletic performance ${ }^{[17-19]}$.

The improvements in quickness and response time have become high priorities in the coaching and conditioning of athletes in the present era. Although many athletes try hard to make themselves focus or concentrate, few fully understand the meaning of 
concentration, and are often left wondering: "How, exactly do I do that?" There are varieties of methods available for improving response time: Mental rehearsal, selective attention practice, improved fitness, identifying cues before movement, warm up and creating optimum levels of arousal. The literature is really sparse when it comes to exploring the influence of biofeedback in optimizing psychomotor activity in sports. The role of EEG biofeedback technology in optimizing psychomotor reactivity has been estimated in musical performers ${ }^{[11,12,20]}$. Thus, the present study aims at:

1) Exploring the influence of HRV BFB on psychomotor reactivity of basketball players.

2) Comparing the results obtained with HRV BFB program to those obtained with the visualization of motivational video clips.

\section{METHODS AND SUBJECTS}

\section{Participants and study design:}

30 basketball players $($ Male $=16$, Female $=14)$ ranging in age from 18 to 28 years $(21.70 \pm 2.71$ years $)$ were recruited from Amritsar. The subjects did not receive any kind of psychological intervention previously and no known medical or psychiatric diagnosis was reported from the participants. The subjects represented a wide range of skills from university (43.3\%), state $(26.7 \%)$ to national $(30 \%)$ standards. Ethical clearance was obtained from the Institutional Ethics Committee of Faculty of Sports Medicine and Physiotherapy, Guru Nanak Dev University, Amritsar, India.

The study was experimental in nature with a double blind study design. The participants were randomly assigned into three equal groups $(\mathrm{N}=10)$ :

1) Experimental Group received Heart rate variability $(\mathrm{HRV})$ biofeedback training $($ Male $=8$, Female=2)

2) Placebo Group was shown motivational basketball visual clips $($ Male $=2$, Female $=8)$

3) Control Group did not receive any training $($ Male $=7$, Female $=3$ )
During the initial visit, players selected according to the inclusion criteria completed an informed consent, a demographic questionnaire and a concentration grid. After filling the questionnaires; a three-minute shooting test was performed. Players were then fitted with a plethysmographic sensor on the finger and abdominal strain gauge for baseline measures of heart rate variability and respiration rate respectively. The study was conducted at the Sports Psychology Lab, Department of Sports Medicine and Physiotherapy, Guru Nanak Dev University, Amritsar, India.

Pre and post recording of the following measures were done.

\section{Psychological measures:}

Concentration was assessed by a Concentration Grid: Concentration grid is a 60 -second exercise containing randomly distributed numbers from 0 to 99 . The aim is to find maximum consecutive numbers starting from zero. The time limit awarded is 60 seconds. Higher scores reveal efficiency in scanning the grid and appropriate focus in completing the task. Good levels of concentration are indicated by the ability to score in the upper 20s and low 30s within a one-minute period of time. A number of testing variations can be performed with this exercise. After the initial testing, a second round of the exercise can be done with external distractions, such as playing loud music. With the second test, participants begin at number 33 to reduce the practice effect. Or, a number at random can be selected as the beginning point or participants can be instructed to start with a particular number and mark consecutive descending numbers or odd or even numbers. Test-retest reliability revealed a correlation of $\mathrm{r}=0.10(P=0.62)^{[21]}$.

\section{Physiological measures:}

Heart rate variability and respiration rate was measured by Biograph Procomp Infiniti 5.0 Thought technology Ltd., Canada (Table 1).

\section{Performance measures:}

Reaction time (choice reaction time) and movement time was measured by Moyart, Lafayette Instrument, U.S.A. Five trials were carried out for visual response time testing and the average of the trials was 
Table 1: Dimensions for each variable

$\begin{array}{lc}\text { Measure } & \text { Dimension } \\ \text { Total HRV } & \mathrm{ms}^{\wedge} 2 / \mathrm{Hz} \\ \text { LF HRV } & \mathrm{ms}^{\wedge} 2 / \mathrm{Hz} \\ \text { HF HRV } & \mathrm{ms}^{\wedge} 2 / \mathrm{Hz} \\ \text { Respiration rate } & \text { breaths } / \text { minute } \\ \text { Concentration } & \text { total score in } 60 \text { seconds } \\ \text { Choice reaction time } & \text { seconds } \\ \text { Movement time } & \text { seconds } \\ \text { Shooting } & \text { total number of shots in } 90 \text { seconds } \\ \text { HRV: Heart } & \text { Rate } \\ \text { Frequency } & \text { Variability; LF: Low Frequency; HF: High }\end{array}$

considered as the reading for choice reaction and movement time (Table 1).

Shooting test: A three-minute shooting test was used. The participant was asked to execute as many shots as possible from any position on a marked perimeter of $366 \mathrm{~cm}$ radius from the hoop for 90 seconds. The participant was responsible for shooting and retrieving the ball himself. Each successful shot earned one point. Test-retest reliability has been reported at $0.91^{[22]}$.

\section{Protocol:}

GROUP A (Experimental group): The protocol designed by ${ }^{[13]}$ for HRV BFB training was implemented with the participants. Following the pretest measurements, the subject was made to sit with closed eyes in a chair for five minutes with hands resting on arm rest in a peaceful room before commencement of HRV biofeedback training. In the first session, the subject was asked to breathe at variable respiratory rates for about two minutes each $(6.5,6,5.5,5,4.5$ breaths/ minute) for determination of resonant frequency. A "pacing stimulus" at a target respiratory rate was provided to the subject. The subject was instructed to breathe at that particular rate. The resonant frequency can be detected as the maximum point in the peak amplitude signal of the resonant frequency detection monitor on the biofeedback equipment. The subject was then asked to breathe at his resonant frequency and relax. The BFB sessions were given for 10 consecutive days for 20 minutes each. The subject was also asked to imagine himself/herself doing the shooting task during the training. The feedback to the subject was given in the form of beat-to-beat heart rate and respiratory rate on the screen. In addition, the subject was taught breathing through pursed lips abdominal procedure to elicit high amplitude oscillations in heart rate at his resonant frequency to achieve a relaxed state.

GROUP B (Placebo group): Subjects were shown motivational basketball video clips for 10 minutes daily for 10 days.

GROUP C (Control group): Subjects in this group did not receive any training.

Players in all the three groups were allowed to continue with their normal practice schedule.

\section{Statistical Analysis:}

The data was statistically analysed using the Statistical Package for Social Sciences (SPSS)/16.0 (Copyright (C) SPSS Inc.). For examining the improvement in the dependent variables on day one, day ten and one month follow-up along with inter-group comparison Two-way Repeated Measure ANOVA was used. Statistical significance was accepted at $P \leq 0.05$. Tukey's HSD post hoc comparison was done to explore intergroup differences and to provide specific information on associated variables.

\section{RESULTS}

\section{Psychological measures:}

The means and standard deviation for pre, post and follow up concentration for the three groups is shown in table 2. Variation in concentration measured over time (i.e. pre, post and follow up) was statistically significant in each group along with interaction of group and time $(F=160.86, P<0.001)$. The inter-group difference in concentration also was statistically significant $(F=39.37, P<0.001)$ (Table 3$)$. However the post-hoc analysis using Tukey's-HSD revealed statistically significant difference between group $1 \mathrm{vs}$. 2 and group 1 vs. 3; whereas no significant difference was found between group 2 vs. 3 (Table 4).

\section{Physiological measures:}

The means and standard deviation for pre, post and follow up total HRV for the three groups is shown in 
Table 2: Mean (standard deviation) of psychological, physiological and performance variables in three Groups

$\begin{array}{llccc}\text { Variables } & \text { Group } & \text { Pre } & \text { Post } & \text { Follow up } \\ \text { Concentration } & \text { Experimental } & 14.70(1.94) & 23.20(1.13) & 23.90(1.10) \\ & \text { Placebo } & 14.70(1.94) & 14.50(2.27) & 14.60(1.64) \\ \text { Total HRV } & \text { Control } & 15.20(1.81) & 14.80(1.93) & 14.90(2.08) \\ & \text { Experimental } & 810.31(817.29) & 2225.6(1624.35) & 2298.6(1642.37) \\ & \text { Placebo } & 761.1(481.57) & 761.05(481.29) & 761.18(481.41) \\ \text { LF HRV } & \text { Control } & 456.07(386.13) & 455.98(386.24) & 456.04(386.08) \\ & \text { Experimental } & 255(218.99) & 1221.9(1009.98) & 1267(1028.18) \\ \text { HF HRV } & \text { Placebo } & 278.58(139.88) & 278.47(139.91) & 278.67(139.65) \\ & \text { Control } & 245.85(227.04) & 245.89(226.74) & 245.88(226.75) \\ \text { Total Respiration rate } & \text { Experimental } & 386.73(462.44) & 670.19(522.45) & 687.48(534.38) \\ & \text { Placebo } & 223.14(115.01) & 222.89(115.21) & 222.76(115.17) \\ \text { Choice Reaction time } & 131.1(121.86) & 131.08(121.94) & 131.01(121.70) \\ & \text { Control } & 15.31(2.00) & 6.25(0.25) & 6.00(0.17) \\ & \text { Experimental } & 15.27(2.15) & 15.28(2.13) & 15.32(2.12) \\ \text { Mocebo } & \text { Control } & 14.61(1.77) & 14.64(1.73) & 14.74(1.73) \\ \text { Mevement time } & \text { Placebo } & 0.432(0.04) & 0.34(0.03) & 0.33(0.03) \\ & \text { Control } & 0.39(0.07) & 0.39(0.07) & 0.38(0.07) \\ \text { Shooting } & \text { Experimental } & 0.42(0.09) & 0.42(0.09) & 0.42(0.09) \\ & \text { Placebo } & 0.31(0.06) & 0.257(0.04) & 0.247(0.04) \\ & \text { Control } & 0.43(0.18) & 0.43(0.18) & 0.43(0.18) \\ & \text { Experimental } & 0.35(0.05) & 0.35(0.05) & 0.35(0.05)\end{array}$

HRV: Heart Rate Variability; LF: Low Frequency; HF: High Frequency

table 2. Variation in Total HRV measured over time (i.e. pre, post and follow up) was statistically significant in each group along with interaction of group and time $(F=20.94, P<0.001)$. The inter-group difference in Total HRV also was statistically significant $(F=6.66, P=0.004)$ (Table 3). However the post-hoc analysis using Tukey's-HSD revealed statistically significant difference between group $1 \mathrm{vs}$. 2 and group 1 vs. 3; whereas no significant difference was found between group 2 vs. 3 (Table 4).

The means and standard deviation for pre, post and follow up LF HRV for the three groups is shown in table 4. Variation in LF HRV measured over time (i.e. pre, post and follow up) was statistically significant in each group along with interaction of group and time $(F=12.76, P<0.001)$. The inter-group difference in LF HRV also was statistically significant ( $F=7.01$, $P=0.004$ ) (Table 3). However the post-hoc analysis using Tukey's-HSD revealed statistically significant difference between group 1 vs. 2 and group 1 vs. 3; whereas no significant difference was found between group 2 vs. 3 (Table 4).
High frequency HRV decreases after the BFB training whereas it increases across the sessions. The means and standard deviation for pre, post and follow up HF HRV for the three groups is shown in table 2. Variation in HF HRV measured over time (i.e. pre, post and follow up) was statistically significant in each group along with interaction of group and time $(F=17.11, P<0.001)$. The inter-group difference in LF HRV also was statistically significant $(F=6.19$, $P=0.006$ ) (Table 3). However the post-hoc analysis using Tukey's-HSD revealed statistically significant difference between group 1 vs. 2 and group 1 vs. 3; whereas no significant difference was found between group 2 vs. 3 (Table 4).

The means and standard deviation for pre, post and follow up Respiration Rate for the three groups is shown in table 3. Variation in Respiration Rate measured over time (i.e. pre, post and follow up) was statistically significant in each group along with interaction of group and time $(F=204.02, P<0.001)$. The inter-group difference in Respiration Rate also was statistically significant $(F=41.84, P<0.001)$ (Table 3 ). 
Table 3: Two-way repeated measure ANOVA for psychological, physiological and performance variables

\begin{tabular}{|c|c|c|c|c|c|c|c|}
\hline Variables & $\begin{array}{l}2 \text { way repeated } \\
\text { measure ANOVA }\end{array}$ & Source & $\begin{array}{l}\text { Sum of } \\
\text { Squares }\end{array}$ & df & $\begin{array}{l}\text { Mean } \\
\text { Square }\end{array}$ & F value & P value \\
\hline \multirow{5}{*}{ Concentration } & \multirow{3}{*}{$\begin{array}{l}\text { Within Subject } \\
\text { Effect }\end{array}$} & Time & 156.29 & 2 & 78.14 & 136.12 & $<0.001$ \\
\hline & & Time x Group & 369.38 & 4 & 92.34 & 160.86 & $<0.001$ \\
\hline & & Error & 31.00 & 54 & 0.57 & & \\
\hline & \multirow{2}{*}{$\begin{array}{l}\text { Between Subject } \\
\text { Effect }\end{array}$} & Group & 678.69 & 2 & 339.34 & 39.37 & $<0.001$ \\
\hline & & Error & 232.70 & 27 & 8.62 & & \\
\hline \multirow{5}{*}{ Total HRV } & \multirow{3}{*}{$\begin{array}{l}\text { Within Subject } \\
\text { Effect }\end{array}$} & Time & 4692515.66 & 2 & 2346257.83 & 20.94 & $<0.001$ \\
\hline & & Time x Group & 9385756.15 & 4 & 2346439.04 & 20.94 & $<0.001$ \\
\hline & & Error & 6050157.51 & 54 & 112039.95 & & \\
\hline & \multirow{2}{*}{$\begin{array}{l}\text { Between Subject } \\
\text { Effect }\end{array}$} & Group & $2.876 \mathrm{E} 7$ & 2 & $1.438 \mathrm{E} 7$ & 6.66 & 0.004 \\
\hline & & Error & $5.827 \mathrm{E} 7$ & 27 & 2158111.85 & & \\
\hline \multirow{5}{*}{ LF HRV } & \multirow{3}{*}{$\begin{array}{l}\text { Within Subject } \\
\text { Effect }\end{array}$} & Time & 2179138.36 & 2 & 1089569.18 & 12.76 & $<0.001$ \\
\hline & & Time x Group & 4357928.81 & 4 & 1089482.20 & 12.76 & $<0.001$ \\
\hline & & Error & 4610753.75 & 54 & 85384.33 & & \\
\hline & \multirow{2}{*}{$\begin{array}{l}\text { Between Subject } \\
\text { Effect }\end{array}$} & Group & 8529024.28 & 2 & 4264512.14 & 7.01 & 0.004 \\
\hline & & Error & $1.643 \mathrm{E} 7$ & 27 & 608640.54 & & \\
\hline \multirow{5}{*}{ HF HRV } & \multirow{3}{*}{$\begin{array}{l}\text { Within Subject } \\
\text { Effect }\end{array}$} & Time & 189608.82 & 2 & 94804.41 & 17.04 & $<0.001$ \\
\hline & & Time x Group & 380716.24 & 4 & 95179.06 & 17.11 & $<0.001$ \\
\hline & & Error & 300366.08 & 54 & 5562.33 & & \\
\hline & \multirow{2}{*}{$\begin{array}{l}\text { Between Subject } \\
\text { Effect }\end{array}$} & Group & 3398564.16 & 2 & 1699282.08 & 6.19 & 0.006 \\
\hline & & Error & 7409793.46 & 27 & 274436.79 & & \\
\hline \multirow{5}{*}{$\begin{array}{l}\text { Total } \\
\text { Respiration } \\
\text { rate }\end{array}$} & \multirow{3}{*}{$\begin{array}{l}\text { Within Subject } \\
\text { Effect }\end{array}$} & Time & 183.03 & 2 & 91.51 & 196.63 & $<0.001$ \\
\hline & & Time x Group & 379.81 & 4 & 94.95 & 204.02 & $<0.001$ \\
\hline & & Error & 25.13 & 54 & 0.46 & & \\
\hline & Between & Group & 675.76 & 2 & 337.88 & 41.84 & $<0.001$ \\
\hline & Effect & Error & 218.02 & 27 & 8.07 & & \\
\hline \multirow{5}{*}{$\begin{array}{l}\text { Choice } \\
\text { Reaction time }\end{array}$} & \multirow{3}{*}{$\begin{array}{l}\text { Within Subject } \\
\text { Effect }\end{array}$} & Time & 0.03 & 2 & 0.013 & 21.15 & $<0.001$ \\
\hline & & Time x Group & 0.04 & 4 & 0.009 & 14.93 & $<0.001$ \\
\hline & & Error & 0.03 & 54 & 0.001 & & \\
\hline & Between & Group & 0.05 & 2 & 0.03 & 1.80 & 0.2 \\
\hline & Effect & Error & 0.40 & 27 & 0.01 & & \\
\hline \multirow{5}{*}{$\begin{array}{l}\text { Movement } \\
\text { time }\end{array}$} & \multirow{3}{*}{$\begin{array}{l}\text { Within Subject } \\
\text { Effect }\end{array}$} & Time & 0.01 & 2 & 0.004 & 62.20 & $<0.001$ \\
\hline & & Time $x$ Group & 0.01 & 4 & 0.004 & 57.35 & $<0.001$ \\
\hline & & Error & 0.003 & 54 & $6.334 \mathrm{E}-5$ & & \\
\hline & \multirow{2}{*}{$\begin{array}{l}\text { Between Subject } \\
\text { Effect }\end{array}$} & Group & 0.38 & 2 & 0.19 & 4.86 & 0.02 \\
\hline & & Error & 1.07 & 27 & 0.04 & & \\
\hline \multirow{5}{*}{ Shooting } & \multirow{3}{*}{$\begin{array}{l}\text { Within Subject } \\
\text { Effect }\end{array}$} & Time & 234.87 & 2 & 117.43 & 151.95 & $<0.001$ \\
\hline & & Time $x$ Group & 234.07 & 4 & 58.52 & 75.72 & $<0.001$ \\
\hline & & Error & 41.73 & 54 & 0.773 & & \\
\hline & \multirow{2}{*}{$\begin{array}{l}\text { Between Subject } \\
\text { Effect }\end{array}$} & Group & 314.07 & 2 & 157.03 & 11.05 & $<0.001$ \\
\hline & & Error & 383.67 & 27 & 14.21 & & \\
\hline
\end{tabular}

HRV: Heart Rate Variability; LF: Low Frequency; HF: High Frequency

However, the post-hoc analysis using Tukey's-HSD revealed statistically significant difference between group 1 vs. 2 and group 1 vs. 3; whereas no significant difference was found between group 2 vs. 3 (Table 4).

\section{Sport performance measures:}

Response time is a measure of performance and is used to evaluate motor skills of an athlete. The means and standard deviation for pre, post and follow up choice 
Table 4: Post-Hoc analysis between different groups in psychological, physiological and performance variables

\begin{tabular}{llccc} 
Variables & Comparison & Group 1 vs. 2 & Group 1 vs. 3 & Group 2 vs. 3 \\
Concentration & Mean Difference & 6.00 & 5.63 & 0.37 \\
Total HRV & P value & $<0.001$ & $<0.001$ & 0.9 \\
MF HRV & Mean Difference & 1017.07 & 1322.15 & 305.08 \\
& P value & 0.03 & 0.005 & 0.7 \\
HF HRV & Mean Difference & 636.07 & 668.77 & 32.70 \\
Total Respiration rate & M value & 0.01 & 0.007 & 0.9 \\
& Mean Difference & 358.54 & 450.41 & 91.87 \\
Choice Reaction time & P value & 0.03 & 0.007 & 0.8 \\
& Mean Difference & -6.10 & -5.4787 & 0.6187 \\
Movement time & Mean Difference & 0.001 & 0.001 & 0.7 \\
Shooting & $\boldsymbol{P}$ value & -0.02 & -0.06 & -0.04 \\
& Mean Difference & -0.16 & 0.2 & 0.5 \\
& $\boldsymbol{P}$ value & 0.01 & -0.08 & 0.08 \\
& 4.13 & 0.3 & 0.3 \\
\hline
\end{tabular}

vs. 2; group 1 vs. 3 and group 2 vs. 3 (Table 4).

Similarly for movement time the means and standard deviation for pre, post and follow up for the three groups is shown in table 2. Variation in movement time measured over time (i.e. pre, post and follow up) was statistically significant in each group along with interaction of group and time $(F=57.35$, $P<0.001)$. The inter-group difference in movement time also was statistically significant $(F=4.86, P=0.02)$ (Table 3). However the post-hoc analysis using Tukey's-HSD revealed statistically significant difference between group 1 vs. 2; whereas no significant difference was found between group 1 vs. 3 ; and group 2 vs. 3 (Table 4).

The means and standard deviation for pre, post and follow up shooting for the three groups is shown in table 2. Variation in shooting measured over time (i.e. pre, post and follow up) was statistically significant in each group along with interaction of group and time $(F=75.72, P<0.001)$. The inter-group difference in shooting also was statistically significant $(F=11.05$, $P<0.001$ ) (Table 3). However the post-hoc analysis using Tukey's-HSD revealed statistically significant difference between group 1 vs. 2 and group 1 vs. 3; whereas no significant difference was found between group 2 vs. 3 (Table 4).

\section{DISCUSSION}

The primary objective of the present study was to explore the usefulness of resonant frequency paced breathing for reflecting the improvement of psychomotor performance in sports. Biofeedback creates awareness and helps in reception of meaningful information by the learner about the performed action. The goal of biofeedback is to increase the voluntary control over the physiological processes that are otherwise outside awareness, using the information about them in the form of an external signal. The results of the present study are in accordance with some of the previous findings ${ }^{[6]}$ who explained that the purpose of biofeedback was to improve performance and enhance learning. The current study indicates that the BFB group exhibited considerable reduction in choice reaction time and movement time post training as compared to placebo and control groups, this mitigation persisted at one month follow up also. The effect of reduction in response time (reaction and movement time) could be attributed to the integration of balance established between sympathetic and parasympathetic systems through HRV BFB training. The wrestlers trained through the HRV BFB procedure demonstrated a significant reduction in reaction time 
compared to no change in control group ${ }^{[23]}$. Reduced response time could also be due to athletes becoming more capable of sharply focusing their attention on the act through concentrating on the paced breathing during HRV BFB training. The increased scores of concentration observed in subjects of the experimental group contribute to the improved quickness and speed of the response (Fig. 1).

This finding of the present study is consistent with the results of a previous study ${ }^{[24]}$. They stated that the quicker reaction time in athletes as compared to better muscular co-ordination and improved performance in the speed and accuracy task. The interdependence between improved levels of concentration and reduced response time reflects the ability of the subject to explore and ameliorate irrelevant cognitive emotions and thoughts which may distract at the time of the task. The productivity and fluency of cognitive processes may serve as a prognostic criterion for the ability to achieve psychomotor learning.

It is very common to see players in pressure situations where they fail to perform at the crucial point of the game as a result of nervousness or may not win the competition. Research indicates that a loss in attentional focus and concentration, memory lapses and high arousal levels due to the release of stress hormones may lead to a stressful situation leading to

detrimental performance ${ }^{[25,26]}$. The heart rate may be increased by slow acting sympathetic activity or decreased by fast acting parasympathetic (vagal) activity. The balance between these systems creates a simultaneous increase and decrease in heart rate which produces an optimal relaxed state. Higher HRV indicates an optimal cooperation between the sympathetic and parasympathetic nervous system and thus, represents an index of emotional expression ${ }^{[16]}$. Total and Low frequency HRV increased post training and at follow up for experimental group while High frequency HRV decreased after HRV BFB training whereas it increased across the sessions. The desired respiration rate of six cycles per minute was achieved in the experimental group after biofeedback training. This helps subjects to alter the amplitude or frequency of HRV and regulate RSA effects through the heart rate baroreflex system ${ }^{[27]}$. The player learns to elicit high amplitude oscillations in the cardiovascular system by practicing paced breathing at his resonant frequency. Findings of physiological measures of the present study are in agreement with preliminary studies ${ }^{[14-16,27]}$ which suggests that the cardiovascular system has the property of resonance at a frequency near $0.1 \mathrm{~Hz}$ (six breaths per minute) reflecting the autonomic control of the body (Fig. 2).

The improved fundamental skill of shooting in experimental group post training and at one month follow up as indicated by the findings of the current

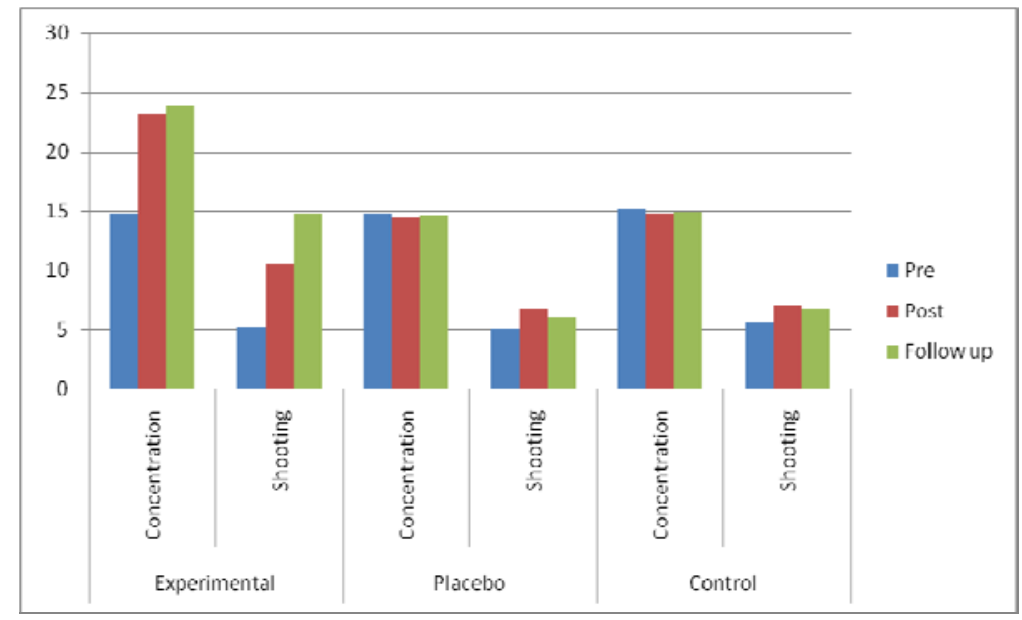

Fig. 1: Intergroup comparison of concentration and shooting for experimental, placebo and control groups 


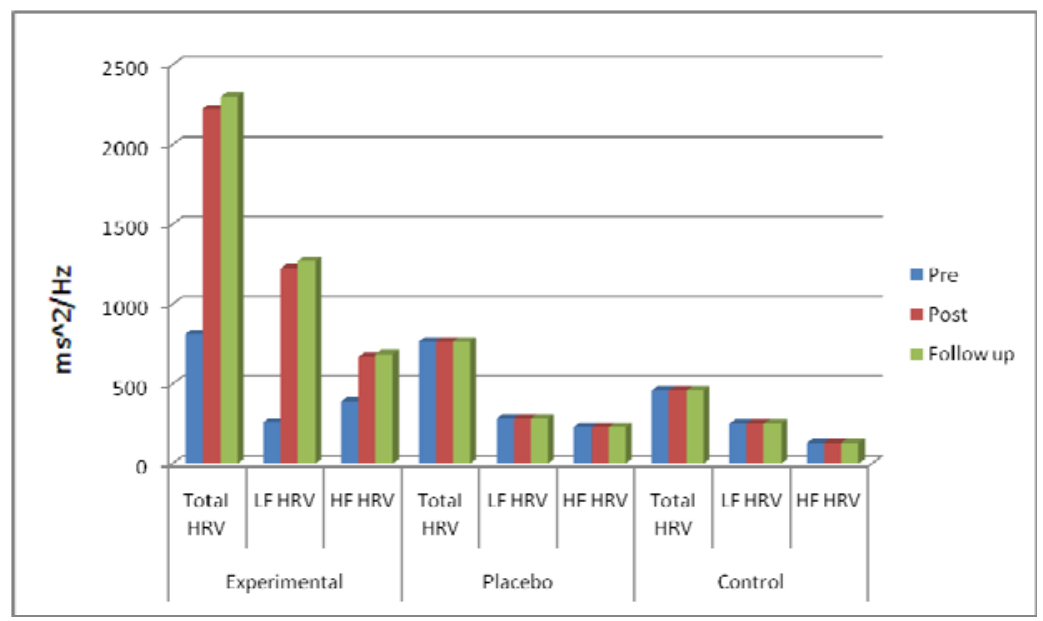

Fig. 2: Intergroup comparison of total HRV, LF HRV and HF HRV for experimental, placebo and control groups

study could be attributed to the HRV BFB training procedure eliciting resonance in the cardiovascular system through a closed loop of baroreflexes. Improved sports performance in the current study is in agreement with the findings of ${ }^{[16]}$ who suggested that HRV BFB training may help the athlete cope with the stress of competition and improve neuromuscular function. HRV BFB training impacted psychological, physiological and sport performance of a collegiate golfer after 10 weeks of training ${ }^{[28]}$. Research studies have also been conducted questioning about HRV BFB and its applications in sports ${ }^{[17-19]}$. Also, the interaction between response time and concentration may have led to statistically significant improvement in shooting as shooting proficiency is determined by concentration, quickness and velocity in sports movements. Self actualization of the shooting task during the BFB training may have assisted in improving the efficacy of training in achieving success. Shooting test showed improvement for placebo and control group post training as the players were involved in their regular practice schedule during the training period and they were allowed to practice fundamental skills of their game.

A notable achievement in the development of cognitive and motor tasks is to learn skills to

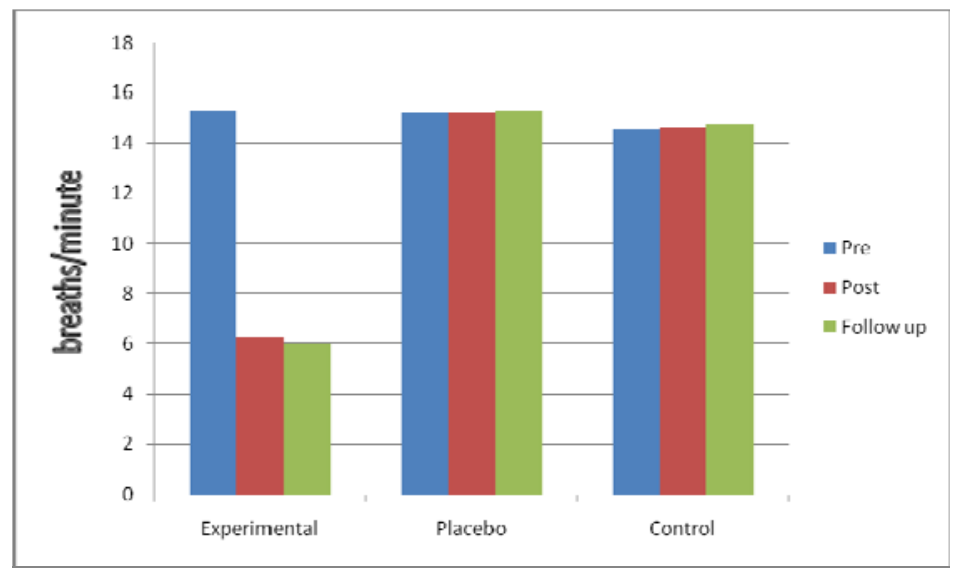

Fig. 3: Intergroup comparison of respiration rate for experimental, placebo and control groups 


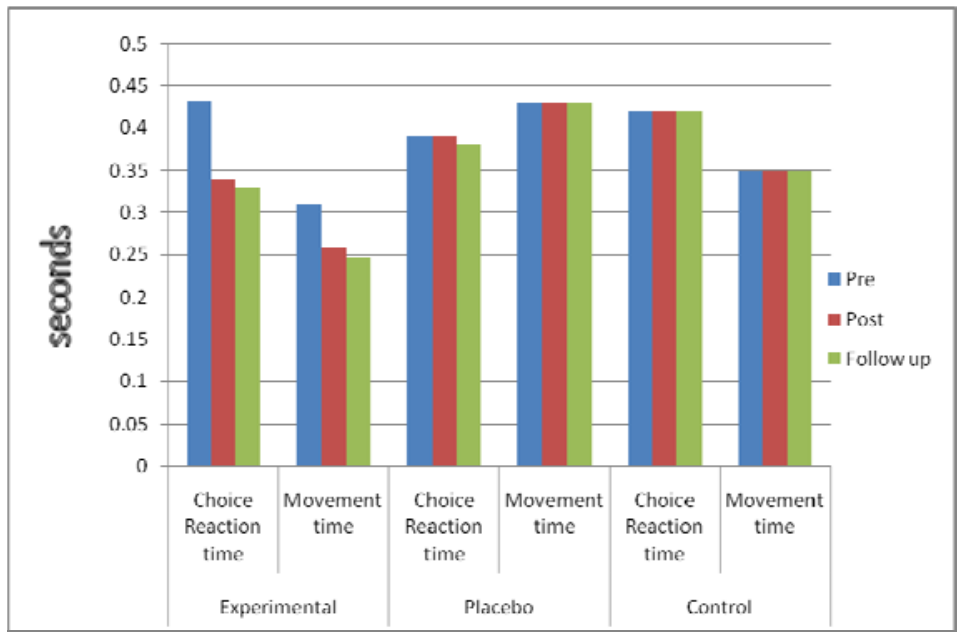

Fig. 4: Intergroup comparison of choice reaction time and movement time for experimental, placebo and control groups

accomplish success and effectively cope with stress and pressure of the game. The state of mental readiness achieved through biofeedback training helps the subject to combat stress and recognize, understand as well as improve his attention level. Subconscious thoughts like tension and pressure of performing "perfect" impairs the attention of an athlete. Thus, biofeedback helps by gaining a control over his ability to concentrate and focus on a desired task, accomplishing maximal performance. The potential interaction of psychomotor skills (response time) with psychological processes (concentration) can mentally and physically tune the performer to respond with a quiet and ready mind.

It is clearly evident from the findings of the present study that HRV BFB training is a reliable and quantitative intervention aimed at quantifying and stimulating the psychomotor performance in sports.

\section{Strength and Limitation of the Study:}

A major strength of the current study was inclusion of placebo group along with experimental and control group. Comparison with placebo group helped in ruling out the Hawthorne effect and evaluated the efficacy of HRV BFB more specifically on the trained players. Further, assessment of the tested measures after training of one month helped in identifying the long term benefits of HRV BFB on sports performance and predicted whether training effects remain consistent over time.

Limitation of the present study is the small sample size. Also, the data was collected from Amritsar only and there was no equal distribution of males and females in each group.

\section{Future Directions:}

Further study is warranted to ascertain the effects of HRV BFB over durations that exceed ten sessions with a larger sample size. This is important as all athletes may not be able to gain self-regulatory skills in ten sessions. Secondly, the HRV BFB intervention may be combined with mental skills and progressive muscle relaxation technique to stimulate physiological and psychological domains more extensively.

Further questions concern how biofeedback can be used as a strategy for stress management in players possessing different skills within the same sport like cricket, football, and hockey. Also, the effect of biofeedback could be judged in elite and novice level players separately.

\section{CONCLUSION}

In summary, the result of the current study infers that resonant frequency biofeedback training may have 
rhythmically stimulated the cardiovascular and respiratory systems of basketball players causing reduction in response time and improving concentration. The heightened autonomic nervous system activity modulated by HRV BFB training leads to normalized autonomic regulation. It can be concluded that HRV dynamics is particularly sensitive to changes in emotional states so an optimally relaxed state of mind may have potentially influenced substantial improvements in an athlete's concentration, shooting performance and response time. Thus, an interesting finding which cropped up from the present study is the influence of biofeedback in creating an optimal tuning between physiological, psychological and psychomotor processes of the human body.

\section{ACKNOWLEDGMENTS}

The authors are thankful to all the players who participated in the study and the study was not funded by any of the resources.

Conflict of interests: None

\section{REFERENCES}

1. Schmidt RA, Lee TD. Motor control and learning: A behavioral emphasis. $3^{\text {rd }}$ ed. Champaign, IL: Human Kinetics. 1999.

2. Schultz RB, Etnyre B, Mc Arthur JM et al. Effects of electromyographic biofeedback on reaction time and movement time. Percept Mot Skills 1987;65:855-9.

3. Namita, Ranjan DP, Shenvi DN. Effect of shift working in reaction time in hospital employees. Indian J Physiol Pharmacol 2010;54: 289-293.

4. Senel O, Eroglu H. Correlation between reaction time and speed in elite soccer players. J Exerc Sci Fitness 2006; 4:126-130.

5. Mannie K. Improving Quickness Response time 2001; Coach and Athletic director, Scholastic Inc, FindArticles.com. 23 Feb, 2011. http://findarticles.com/p/articles/mi_m0FIH/is_9_70/ai_n18611822/

6. Schultz RB, Etnyre B, Mc Arthur JM et al. Effects of electromyographic biofeedback on reaction time and movement time. Percept Mot Skills 1987;65:855-9.

7. Rossiter TR, La Vaque TJ. A comparison of EEG Biofeedback and Psychostimulants in treating attention deficit/ hyperactivity disorders. J Neurother 1995;1:48-59.

8. Mayotte Tim. Tim Mayotte's Pro Diary 1984. Tennis. February 1994.

9. Ziv G, Lidor R. Vertical jump in female and male basketball players-A review of observational and experimental studies. J Sci Med Sport 2009;433:1-8.

10. Malone LA, Gervais PL, Steadward RD. Shooting mechanics related to player classification and free throw success in wheelchair basketball. J Rehabil Res Devel 2002;39:701-710.

11. Bazanova OM, Shtark MB. Biofeedback in optimizing Psychomotor Reactivity: I. Comparison of biofeedback and common performance practice. Human Physiol 2007;33:400-8.

12. Bazanova OM, Verevkin EG, Shtark MB. Biofeedback in optimizing Psychomotor Reactivity: II. The dynamics of segmental $\alpha$ activity characteristics. Human Physiol 2007;33:695-700.

13. Lehrer P M, Vaschillo EG, Vaschillo B. Resonant frequency biofeedback training to increase cardiac variability: Rationale and manual for training. Appl Psychophysiol Biofeedback 2000;25:177-91.

14. Hassett AL, Radvanski DC, Vaschillo EG, et al. A pilot study of the efficacy of heart rate variability (HRV) biofeedback in patients with fibromyalgia. Appl Psychophysiol Biofeedback 2007;32:1-10.

15. Lehrer P, Vaschillo E, Lu SE, Eckberg D et al. Heart rate variability Biofeedback: Effects of age on heart rate variability, baroreflex gain, and Asthma. Chest 2006;129:278-84.

16. Lagos L, Vaschillo E, Vaschillo B et al. Heart rate variability biofeedback for dealing with competitive anxiety: A Case Study. Applied Psychophysiology and Biofeedback 2008;36:109-15.

17. Raymond J, Sajid I, Parkinson L A et al. Biofeedback and dance performance: A preliminary investigation. Appl Psychophysiol Biofeedback 2005;30:65-73.

18. Strack William B. Effect of heart rate variability (HRV) biofeedback on batting performance in baseball. Dissertation Abstracts International: Section B, the Sciences and Engineering 2003;64:1540B. 
19. Vaschillo E G, Rishe N. Therapeutic method for a human subject 1999. U.S. patent 5,997,482. December 7.

20. Bazanova OM, Mernaya EM, Shtark MB. Biofeedback in psychomotor training. Electrophysiological basis. Neurosci Behav Physiol 2009;39:437-47.

21. Harris DV, Harris BL. Athlete's guide to sports psychology: Mental skills for physical people. New York: Leisure Press.1984; Pp: 189.

22. Weinberg R S, Fowler C, Jackson A et al. Effect of goal difficulty on motor performance: A replication across tasks and subjects. $J$ Sport Exerc Psychol 1991;13:160-173.

23. Vaschillo EG, Vysochin YV, Rishe N. RSA biofeedback as an effective relaxation method. Appl Psychophysiol Biofeedback 1998;23:136-137.

24. Kaur P, Paul M, Sandhu JS. Auditory and visual reaction time in athletes, healthy controls, and patients of type 1 diabetes mellitus: A comparative study. Int J Diabetes Devel Countries 2006;26:112-115.

25. Fitts PM, Posner MI. Human Performance. Belmont; CA: Brooks/Cole.1967.

26. Maxwell JP, Masters RW, Eves FF. From novice to know how: A longitudinal study of implicit motor learning. J Sport Sci 2000;18:111-120.

27. Lehrer P, Vaschillo E, Vaschillo B et al. Heart rate variability biofeedback increases baroreflex gain and peak expiratory flow. Psychosom Med 2003;65:796-805.

28. Lagos L, Vaschillo E, Vaschillo B et al. Virtual Reality- Assisted HRV BFB as a strategy to improve Golf Performance: A Case Study. Appl Psychophysiol Biofeedback 2011;39:15-20. 